\title{
DESARROLLO Y EVOLUCIÓN DEL PENSAMIENTO DEL JOVEN HEIDEGGER'
}

Jesús Adrián Escudero

Universidad Autónoma de Barcelona

El presente trabajo analiza el desarrollo de la obra temprana de Heidegger en torno a dos ejes principales: por una parte, un eje temático que gira en torno a los diferentes intentos de articular conceptualmente un análisis en clave ontológica de los modos de ser de la vida fáctica y, por otra, un eje metodológíco que explica la función y el alcance de la llamada transformación hermenéutica de la fenomenología llevada a cabo por Heidegger durante sus primeros años de magisterio en Friburgo.

Palabras clave:

vida fáctica, ontología, hermenéutica fenomenológica, destrucción, Heidegger

I El presente trabajo se enmarca en el proyecto de investigación financiado por el Ministerio de Ciencia e Innovación (FFI2009-13I87FISO) y del Fellowship for Advanced Researchers de la Humboldt-Foundation. 
Cada filósofo piensa un solo pensamiento, como gustaba recordar Heidegger en sus lecciones. A estas alturas, ya no resulta ninguna novedad afirmar que el rasgo que define el pensamiento de Heidegger es la pregunta por el sentido del ser. Él mismo ha confirmado este hecho en múltiples declaraciones autobiográficas. Sin embargo, lo que en la actualidad todavía puede despertar el interés del lector de Ser y tiempo, a medida que los primeros cursos universitarios del período de juventud han ido saliendo a la luz, es observar cómo el horizonte de esa pregunta se va perfilando en el contexto de un rico juego de superposiciones filosóficas que, de una u otra manera, intenta recorrer el camino que conduce de la vida humana a la cuestión del ser. El pensamiento del joven Heidegger se mueve por este sendero, volviendo recurrentemente sobre los pasos de la tradición filosófica con el fin de alcanzar una comprensión originaria de la existencia humana. En sus primeros años de doctorando, comienza su andadura filosófica entre la rigurosidad de la teología católica y la sistematicidad del neokantismo imperante en las aulas universitarias alemanas de principios del siglo XX. Pero no tarda mucho en distanciarse de este clima intelectual excesivamente formal y apartado de las cuestiones de la vida real. En el período de posguerra, empieza a bucear en las fuentes de los místicos medievales y las epístolas paulinas, los escritos de Agustín y de Lutero en el marco de unas exploraciones filosóficas que giran en torno a la constitución ontológica de la vida humana. Todo ello se enmarca en un precoz descubrimiento de la fenomenología de Husserl y su capacidad de llegar a la raíz de las cosas mismas. A pesar de sus profundas diferencias con la fenomenología transcendental de Husserl, este último ya no le abandonará, al igual que la hermenéutica de Dilthey y, sobre todo, la filosofía práctica de Aristóteles. Son, sin duda, tres personajes fundamentales a la hora de comprender el itinerario filosófico y académico de un joven Heidegger empeñado en repensar el sentido del ser en toda su radicalidad.

Ahora bien, ¿cuál es el hilo conductor de su pensamiento?, ¿en qué momento empieza a cristalizar su programa filosófico de juventud?, ien torno a qué temas se articula?, ¿cómo se reinterpreta la fenomenología husserliana en clave hermenéutica?, ¿qué papel desempeñan autores como Aristóteles, Kant, Dilthey y Husserl en este período?, ¿cuál es el clima intelectual en el que se mueve el pensamiento heideggeriano durante los años veinte? En el presente trabajo se responde a las siguientes tres cuestiones. En primer lugar, se dibuja el contexto histórico y cultural en el que se enmarca el desarrollo del 
pensamiento del joven Heidegger. En segundo lugar, se traza el hilo conductor del pensamiento del joven Heidegger, que no es otro que el de la pregunta por el ser de la vida fáctica. Y, en tercer lugar, se esbozan los ejes fundamentales de la ontología de la vida humana que se remonta a sus primeras lecciones de 1919 en torno a una ciencia originaria de la vida y cristaliza finalmente en 1927 en la conocida analítica existenciaria.

\section{§ 1. Contexto cultural}

Los primeros años que Heidegger ejerce como profesor en la Universidad de Friburgo, entre 1919 y 1923, nos presentan a un pensador inconformista e inquieto, enfrascado en el ambicioso proyecto de dotar a la filosofía de un nuevo sentido. Sus constantes y fructíferas investigaciones en el terreno de la teoría neokantiana del conocimiento, en el ámbito de la tradición teológica, en la esfera de las diferentes corrientes vitalistas, en el horizonte de la hermenéutica de Dilthey y, sobre todo, en el contexto de la fenomenología de Husserl y de la filosofía práctica de Aristóteles muestran los esfuerzos de alguien que persigue con afán dotar a la vida y a la filosofía de un significado que traspase los blindados muros del mundo académico, de alguien que con ahínco quiere sacudirse el yugo de una visión determinista del hombre. Nos hallamos ante un joven Heidegger que no es ajeno al pathos expresionista que invade el clima cultural alemán de posguerra. Artistas, literatos, sociólogos, antropólogos, historiadores y filósofos, alarmados por la amenaza de un determinismo férreo, alzan al unísono un grito de protesta contra el optimismo de la razón positivista y buscan devolver al pensamiento la libertad y la dignidad de la que había gozado un siglo antes. Ante esta tesitura, emerge toda una nueva constelación de intelectuales de diversa índole que va a marcar el espíritu de una época: Kirchner, Kandinsky y Klimt en la pintura; Mahler y Schönberg en la música; Dilthey, Husserl, Cassirer, Jaspers, Scheler y Heidegger en la filosofía; Brecht, Hofmannsthal, Mann, Rilke y George en la literatura; Ehrenfelds, Weininger y Freud en la psicología; Gropius, Loos y Wagner en la arquitectura; Ranke, Troeltsch y Meinecke en la historia; Planck, Mach y Einstein en la ciencia; Weber, Simmel, Spengler y Mannheim en la sociología. Unos y otros tratan de resolver el dilema de cómo volver a captar la inmediatez de las experiencias humanas en el seno de una realidad social fragmentada y sin valores. 
En todas estas disciplinas se produce lo que Lukàcs caracterizó gráficamente como un "asalto a la razón", lo que significa: poner en tela de juicio la indefinición ideológica, criticar la masiva utilización de la propaganda, poner de relieve la indoctrinación de la sociedad, denunciar la emergencia de mentalidades totalitarias, alimentar la desconfianza hacia todo discurso político, sacar a la superficie las bolsas de pobreza de una ética capitalista feroz. No es de extrañar que, en este contexto, surjan preguntas en torno a la deformación ideológica de la realidad, a la manipulación de la información, a las estrategias propagandísticas, al papel de los intelectuales, al desarraigo existencial. Un crudo diagnóstico de la realidad que, a su manera, ya había avanzado Nietzsche en las Consideraciones intempestivas al retratar la situación cultural alemana como una época dominada por profesores y tecnócratas, militares y funcionarios. No se puede ser al mismo tiempo hombre de acción y hombre de estudio sin atentar contra la dignidad de una y otra profesión, un tema que luego retoma Max Weber en La vocación interna de la ciencia (1919) y Oswald Spengler en La decadencia de Occidente (1922), por citar dos obras del momento que Heidegger conocía a la perfección ${ }^{2}$. Sin duda, el libro de Spengler marcó a toda una generación de intelectuales, pensadores y artistas alemanes de los años de posguerra. Según el diagnóstico de Spengler, Occidente se ha atomizado y disgregado bajo el triunfo de las ciencias, pero carece de un espíritu colectivo y patrio (Volkgeist). Eso explica, en parte, la fuerza con la que la sociedad alemana se une ante la adversidad, especialmente ante las draconianas sanciones económicas que impuso la Paz de Versalles, como muy bien dejó entrever John Keynes en Las consecuencias económicas de la paz (1919).

\footnotetext{
2 Más detalles sobre el clima intelectual en el que transcurrió esta productiva etapa de la vida de Heidegger en: Ott, H., Martin Heidegger. En camino de su biografía, Madrid: Alianza Universidad, 1992, pp. II7-I32; Nolte, E., Heidegger. Política e historia en su vida y pensamiento, Madrid: Tecnos, 1998; Safranski, R., Un maestro de Alemania. Heidegger y su tiempo, Barcelona: Tusquets, 1997, pp. I0I-I37. Y para un cuadro general del contexto histórico, político y social de estos años, véanse: Fergusson, A., Cuando muere el dinero. El derrumbamiento de la República de Weimar, Madrid: Alianza Editorial, 1984; Gay, P., La cultura de Weimar. La inclusión de lo excluido, Barcelona: Argos, 1984; Hughes, H.S., Conciencia y sociedad. La reorientación del pensamiento social europeo, Madrid: Aguilar, 1972; Watson, P., Historia intelectual del siglo XX, Barcelona: Crítica, 2002. Y sobre el marco específicamente filosófico de este período, consultar: Bambach, Ch., "German Philosophy between Scientism and Historicism", en: Heidegger, Dilthey and the Crisis of Historicism, Ithaca/Londres: Cornell University Press, 1995, pp. 2I-56; Gadamer, H.-G., "Sobre la filosofía alemana en el siglo XX", en: ER. Revista de Filosofia, XXVI (2000), pp. I89-2 I7; Barash, J.A., "The Emergency of Historical Meaning in Nineteenth-Century German Thought", en: Martin Heidegger and the Problem of Historical Meaning, La Haya: Martinus Nijhoff, 1988, pp. 17-89.
} 
El pensamiento del joven Heidegger se enmarca en este clima de desasosiego intelectual, de inhospitalidad existencial y de desazón espiritual de una época dominada por el ocaso de los héroes. Encontramos múltiples retratos de una sociedad fragmentada y de falta de ídolos en obras como El hombre sin atributos de Robert Musil, La montaña mágica de Thomas Mann, Ulises de James Joyce, La metamorfosis de Franz Kafka y, de una manera muy gráfica, en El grito de Munch y en la película El Gabinete del Dr. Caligari. Así pues, no es de extrañar que ante este desolador panorama de la sociedad alemana emerjan espontáneamente preguntas relacionadas de una u otra manera con el sentido de la existencia humana: ¿qué hacer ante una civilización que navega a la deriva?, icómo escapar a una racionalidad técnica que calcula todas las variables de la existencia humana, que elimina toda huella de individualidad, que somete la voluntad personal al orden causal de las ciencias? El espíritu se siente aprisionado y desconfía del discurso positivista que pretendía construir una sociedad ideal y gobernar racionalmente el curso de la historia. La vida necesita abrirse paso y romper con falsas concepciones del mundo. Hay que volver la mirada hacia la realidad, penetrar en su verdadero misterio, vivir según su propia esencia. "La nueva vida que nosotros queremos, o que quiere en nosotros -comenta Heidegger en una carta dirigida a Elisabeth Blochmann en 1919-, ha renunciado a ser universal, es decir, inauténtica, plana y superficial; su posesión es originalidad, no lo artificioso y construido, sino lo evidente de la intuición total”3. Por tanto, hay que hacer frente a la torturante cuestión de cómo volver a captar la inmediatez de la experiencia vivida en un lenguaje que tradicionalmente diseca y almacena la complejidad de la realidad humana en los compartimentos estancos de la memoria lógica. La postura de Heidegger frente a este modo de proceder es tajante: hay que romper con ese lenguaje tradicional; hay que desconfiar del entramado conceptual de la metafísica; hay que fluidificar las categorías que se aplican a la hora de analizar el fenómeno de la vida; en definitiva, hay que practicar una constante hermenéutica de la sospecha para devolver al individuo la capacidad de pensamiento y de acción.

La filosofía tiene que transgredir el orden establecido, ir al fondo de las cosas mismas. Vivir filosóficamente equivale a vivir arriesgadamente y pensar contra las normas prefijadas. Se precisa, por tanto, de hombres con carisma

3 Heidegger, M. y E. Blochmann, Briefwechsel 1918-1969, Múnich: Piper, 1989, carta del I de mayo de 1919. 
capaces de renovar las viejas estructuras de pensamiento y de comportamiento. El joven Heidegger se hace eco de esta llamada, asumiendo ya en sus primeras lecciones de 1919 el reto de elaborar una nueva idea de la filosofía. Nos hallamos -como comenta Heidegger en un tono henchido de pathos expresionista- ante la encrucijada que decide sobre "la vida o la muerte de la filosofía"4. Estamos ante uno de los momentos filosófica y personalmente más decisivos de la vida de Heidegger. Por una parte, se consuman su ruptura con el sistema del catolicismo y su matrimonio protestante con Elfride Petri ${ }^{5} ; \mathrm{y}$, por otra parte, se detectan claros síntomas de distanciamiento con respecto a su sólida formación teológica y neokantiana que apuntan hacia la elaboración de una hermenéutica de la vida fáctica. En este sentido, Karl Löwith destaca con agudeza el rasgo existencial de la persona de Heidegger: "Jesuita por su educación, se volvió protestante por reacción, dogmático escolástico por su formación, pragmático existencial por su experiencia, teólogo por tradición y ateo como investigador". Diferentes rostros de una persona que intenta aprehender un fenómeno tan misterioso, resbaladizo y confuso como el de la existencia humana en su desnuda facticidad. La vida se presenta al joven Heidegger como un enigma que pide ser comprendido. El desciframiento de ese enigma determina en buena medida su itinerario filosófico.

\footnotetext{
4 Heidegger, M., Die Idee der Philosophie und das Weltanschauungsproblem, en: Zur Bestimmung der Philosophie (GA 56/57), Frankfurt del Meno: Vittorio Klostermann, 1987, p. 62.

5 Documentado en la conocida carta del 9 de enero de 1919 remitida a su amigo el sacerdote Engelbert Krebs (en: Casper, B., "Martin Heidegger und die theologische Fakultät Freiburg", Freiburger Diözesan-Archiv, No. 100 [1980], p. 54I) y luego matizado en las cartas a Kart Löwith del 19 de agosto de 1921 y del 20 de agosto de 1927, en las que se define como un "teólogo cristiano", es decir, como alguien interesado en penetrar en el sentido último de la vida religiosa, en mantenerse alejado de posiciones dogmáticas para zambullirse en la corriente vital de la existencia humana (en: Papenfuss, D.y O. Pöggeler [eds.], Zur philosophischen Aktualität Heideggers II, Frankfurt del Meno: Vittorio Klostermann, 1990, pp. 29 y 36-37, respectivamente). De ello dan testimonio sus lecciones de 1920/2I Fenomenología de la vida religiosa, en las que ofrece una serie de sugestivas interpretaciones de la mística de Eckhart, Bernardo de Claraval y Teresa de Ávila, de las epístolas paulinas, de las Confesiones de Agustín, de las Disputaciones de Lutero y de los Discursos sobre religión de Schleiermacher.
}

64 Löwith, K., Mein Leben in Deutschland vor und nach 1933, Stuttgart: Metzer, 1986, p. 45. 


\section{\$ 2. La pregunta por el ser de la vida fáctica como hilo conductor del pensamiento del joven Heidegger}

¿Qué significa ser? Esta es la pregunta que Heidegger se planteó una y otra vez desde sus años de estudiante hasta el final de su vida ${ }^{7}$. Sin duda, la problemática acerca del ser constituye el eje temático que articula su densa actividad filosófica y dibuja el horizonte dentro del cual se ha de abordar cada aspecto concreto de su obra. Ser y tiempo arranca con el firme propósito de una "elaboración concreta de la pregunta por el sentido del 'ser"”'. Pero, ¿qué se entiende realmente por ser?, ¿por qué es tan urgente y necesario replantear la pregunta acerca de su sentido? Una respuesta adecuada a estos interrogantes solo se consigue tomando en consideración la discusión heideggeriana con la tradición filosófica. La aceptación ciega y acrítica del significado del ser transmitido por la tradición es la principal responsable del olvido sistemático en el que ha caído esta cuestión fundamental para el pensamiento. La filosofía moderna de la subjetividad solo ha contribuido a agudizar esta situación hermenéutica de olvido, a partir de la cual se justifica la necesidad de un replanteamiento radical que se remonta hasta los orígenes de la filosofía griega.

Fue Aristóteles quien, basándose en Parménides, formuló la cuestión: ¿qué es el ente?, o más exactamente: ¿qué es el ente en cuanto ente? Sin embargo, esta forma de preguntar pone en circulación un modo determinado de comprender el sentido del ser a partir del ente. Por "ente" se entiende todo aquello que es. En este sentido, la piedra, la planta, el animal y el hombre son entes. Al definir el ente como aquello que es, lo hacemos desde la comprensión previa de otra cosa. "¿De qué se ocupará entonces la filosofía, si no es precisamente del ente, de lo que es, así como del ente en general? (...) ¿Qué

\footnotetext{
7 Una cuestión presente desde su precoz lectura en 1907 del libro de Brentano sobre el significado del ente en Aristóteles hasta su última carta oficial, redactada dos semanas antes de su muerte $y$ dirigida a los participantes del $X^{\circ}$ Coloquio Heidegger celebrado en Chicago (cf. Heidegger, M., "Grußwort an die Teilnehmer des zehnten Colloquiums vom 14-16. Mai 1976 in Chicago [II. April 1976]", en: Reden und andere Zeugnisse eines Lebensweges (GA 16), Frankfurt del Meno: Vittorio Klostermann, 2000, pp. 747-748). Cf. declaraciones autobiográficas semejantes en: Heidegger, M., “Mein Weg in die Phänomenologie”, en: Zur Sache des Denkens, Tubinga: Max Niemeyer, 1976, pp. 81-92; Prefacio a la primera edición del volumen primero de la Gesamtausgabe (Obras completas), en: Heidegger, M., Frühe Schriften (GA I), Vittorio Klostermann, Frankfurt del Meno, 1978, pp. 55-57.

8 Heidegger, M., Sein und Zeit, Tubinga: Max Niemeyer, 1986, p I.
} 
puede haber además de la naturaleza, la historia, dios, el espacio, el número? De todas y cada una de estas cosas decimos, aunque en diferente sentido: es. Las llamamos ente. Al referirnos a ellas, tanto teórica como prácticamente, nos comportamos de un modo u otro respecto de un ente. (...) En definitiva, hay algo que tiene que haber para que se nos haga accesible el ente como ente y nos podamos comportar respecto de él, algo que, sin duda, no es, pero que debe haber para experimentar y comprender algo como el ente. Somos capaces de comprender al ente como tal sólo si entendemos algo como el ser. Si no comprendiéramos, aunque fuera de modo tosco e impreciso, lo que significa realidad, lo real permanecería para nosotros oculto. (...) Debemos comprender el ser para estar en disposición de que se nos dé un mundo que es, para existir en él y para que nuestro propio Dasein que es pueda ser. Hemos de poder comprender la realidad antes de toda experiencia de lo real. Esta comprensión de la realidad o, en el sentido más amplio, del ser, es en un sentido determinado anterior respecto de la experiencia del ente"'. Este nivel último e irreductible de realidad que trasciende todo lo inmediatamente dado recibe el nombre de "ser".

Ahora bien, ies posible representarse algo así como el ser? Al intentarlo, quedamos perplejos. La filosofía de Heidegger gira precisamente en torno al reconocimiento de que el ser no se puede tematizar, es decir, que no es un objeto de estudio del que se pudieran enunciar sus propiedades. El ser no es ningún ente $y$, por tanto, ningún objeto que pueda ser representado. Media entre ellos una diferencia ontológica insalvable. Tampoco puede definirse. Hay que remontarse a la precomprensión que el ser humano ya tiene siempre del ser. Así pues, solo queda la alternativa de mostrarlo partiendo de la experiencia ontológica que acabamos de evocar: el ser está de algún modo dado en todo ente. El ser suministra la comprensión que está presente en cada comportamiento respecto del ente. Pero comportarse respecto del ente es propio de un ente determinado que somos nosotros mismos, el ser humano, el Dasein. El ente que pregunta deviene así el objeto mismo de la pregunta.

Y, por otra parte, icómo hay que entender al hombre en su relación con el ser?, icomo zoon logon echon, animal rationale, espíritu, sujeto, autoconciencia?

9 Heidegger, M., Die Grundprobleme der Phänomenologie (GA 24), Frankfurt del Meno: Vittorio Klostermann, 1989, pp. 13-14, cursiva del autor. 
Heidegger rechaza todas estas concepciones del ser humano, porque fundan sus diferentes modos de acceso a las cosas en la percepción sensible y la razón; en otras palabras, porque comprenden la realidad de las cosas existentes en el mundo exclusivamente desde el prisma de la teoría. Heidegger reprocha a la tradición antigua y moderna no haber distinguido con claridad la esencia del hombre de la esencia de las cosas, hasta el punto de haber determinado categorialmente al ser humano como algo existente ahí delante. Su innovadora propuesta de comprender al hombre como un ente caracterizado por el cuidado (Sorge) pone el acento en la relación primariamente práctica que aquel establece con la realidad en el contexto de sus proyectos limitados de acción como ser finito, histórico y temporal. Desde esta perspectiva, el Dasein se entiende como un proyecto arrojado (geworfener Entwurf) y ya no como un ser racionalmente transparente, soberanoy autónomo. Esta nueva concepción del "sujeto" humano es lo que separa a Heidegger de la tradición filosófica. A la naturaleza de este Dasein pertenece la existencia y la posibilidad de comprender el ser. En esta comprensión del ser inherente al Dasein encontramos un terreno de manifestación del ser en general. La pregunta por el ser, pues, remite indefectiblemente al hombre. Solo desde la íntima copertenencia de ser y Dasein resulta viable tal pregunta. "El Dasein no es tan sólo un ente que se presenta entre otros entes. Lo que lo caracteriza ónticamente es que a este ente le va en su ser este mismo ser. La constitución de ser del Dasein implica entonces que el Dasein tiene en su ser una relación de ser con su ser. Y esto significa, a su vez, que el Dasein se comprende en su ser de alguna manera y con algún grado de explicitud. La comprensión del ser es, ella misma, una determinación de ser del Dasein"'. A partir de este hecho se hace evidente que el Dasein presenta un modo de acceso señalado al ser.

En última instancia, el hecho de que en nuestro comportamiento cotidiano y prefilosófico distingamos sin mayores dificultades entre útiles, artefactos, objetos naturales, estados de cosas y contextos de acción responde a que nos movemos siempre y en cada caso en una atemática comprensión previa de sus respectivos modos de ser. Heidegger denomina esta precomprensión del estado de abierto del ser en general terminológicamente el "ahí" (Da).

${ }^{10}$ Heidegger, Sein und Zeit, p. 12, cursivas del autor. 
Por ello, el ser humano recibe el nombre de "ser-ahí", de "Dasein"", porque en su existencia fáctica y concreta ( $D a)$ se manifiesta el ser (Sein). El hombre está ahí, en la apertura del mundo, pero está ahí como el ahí del ser, como el lugar óntico donde el ser se revela, como el ente privilegiado en el que el ser adviene a la luz'2. Pero dado que los modos de manifestación de ese ahí son diversos y varían según la situación y los intereses de cada cual, la pregunta por el ser se interesa por la unidad del sentido de esas múltiples modalidades de ser. "Sentido" significa aquí tanto como el horizonte transcendental desde el que comprendemos en cada caso el ser del ente. Este nexo entre sentido del ser y Dasein resulta decisivo a la hora de plantear correctamente la pregunta fundamental acerca del ser. Si el sentido del ser en general está de algún modo "dado" en la comprensión del ser del Dasein existente, surge inmediatamente la necesidad de realizar un primer análisis preparatorio de la constitución ontológica de ese Dasein.

De este modo, se puede afirmar que la pregunta que realmente atraviesa el pensamiento del joven Heidegger es aquella por el sentido del ser de la vida humana. La vida humana y su comprensión previa del ser constituyen las arterias que alimentan su obra temprana. La riqueza de referencias que

" Heidegger utiliza la expresión Dasein exclusivamente para indicar la constitución ontológica de la vida humana caracterizada por su apertura $(\mathrm{Da})$ al ser (Sein) y por la capacidad de interrogarse por su sentido. El término "Dasein" empieza a adquirir un valor técnico en el Informe Natorp (1922) para señalar al ente que se interroga acerca de su propio ser. Este significado se consolida plenamente en las lecciones de 1923, Ontología. Hermenéutica de la facticidad, en las que Heidegger lo determina en su valor de indicación formal como el modo de ser propio de la existencia humana. Cabe señalar que Heidegger recurre a veces a la grafía Da-sein. El guión resalta la apertura constitutiva del Dasein, una apertura previa y originaria, que no debe confundirse con un aquí meramente local; esa apertura se define en los años posteriores a Ser y tiempo en términos de Seinslichtung ("claro del ser"). De hecho, como comenta Leyte, quizá sea esta la única forma posible de traducir "Dasein". El valor del guión, más allá de señalar la marca física de la separación que mantiene unidos los dos márgenes, resalta la idea de un tránsito continuo, de un permanente "entre". Ese "entre", ese "espacio abierto", ese "tránsito" es lo que Heidegger realmente intenta pensar. Para más información, véase: Leyte, A., Heidegger, Madrid: Alianza Editorial, 2005, pp. 46-47; Adrián, J., El lenguaje de Heidegger. Diccionario filosófico (1912-1927), Barcelona: Herder, 2009, pp. 63-67.

12 En la Introducción de 1949 al texto “¿Qué es metafísica?", Heidegger justifica el recurso al término "Dasein" de la siguiente manera: “(...) a fin de pensar en una sola palabra y a un mismo tiempo tanto la referencia del ser a la esencia del hombre como la relación esencial del hombre con la apertura (el 'ahí') del ser como tal, se eligió para ese ámbito esencial en el que se encuentra el hombre como hombre la palabra ‘Dasein'. (...) Con ‘Dasein' se nombra eso que todavía tiene que ser experimentado $y$, por ende, tiene que ser pensado como lugar, concretamente como el lugar de la verdad del ser” (Heidegger, M., “Einleitung zu 'Was ist metaphysik?' ”, en: Wegmarken [GA 9], Frankfurt del Meno: Vittorio Klostermann, 1979, pp. 372-373). 
pueden encontrarse en esta fructífera etapa docente del pensador ofrece un cuadro muy fidedigno de la genealogía de esa pregunta y de los diferentes requisitos metodológicos para abordarla con garantías. En este sentido, la obra temprana de Heidegger se articula alrededor de dos ejes fundamentales: por una parte, un eje temático que gira en torno a un análisis sistemático de las estructuras ontológicas del Dasein, que marca el punto de partida y suministra el hilo conductor $y$, por otra, un eje metodológico que descansa en una transformación hermenéutica de la fenomenología.

\section{§ 3. Los ejes de la obra temprana de Heidegger}

En el período que se extiende entre 1919 y 1923, los primeros años en los que Heidegger ejerce de profesor contratado en la Universidad de Friburgo, se va fraguando un pensamiento profundamente original, en tensión constante y fructífera con la tradición teológica, con la filosofía académica del neokantismo, con la hermenéutica, con las diversas corrientes de la filosofía de la vida y, sobre todo, con la filosofía práctica de Aristóteles y la fenomenología de Husserl. En este sentido, se puede afirmar que el programa filosófico del joven Heidegger queda esencialmente fijado a partir de los primeros cursos de Friburgo y toma cuerpo definitivamente en los cursos de Marburgo.

La publicación de las lecciones de ese período permite hoy en día comprender mejor y reconstruir con mayor exactitud su temprano itinerario filosófico. Nos referimos, en concreto, a las lecciones del semestre de posguerra de 1919, La idea de la filosofía y el problema de la concepción del mundo, y a las del semestre de verano de ese mismo año, Fenomenología y filosofía transcendental de los valores, a los cursos del semestre de invierno de 1919/20, Problemas fundamentales de la fenomenología, y a los del semestre de verano de 1920, Fenomenología de la intuición y de la expresión. Asimismo, dos escritos de la misma época, Observaciones a la (Psicología de las concepciones del mundo〉 de Karl Jaspers (1919/21) y el llamado Informe Natorp (1922), permiten ilustrar y sustentar definitivamente una tesis de continuidad en el pensamiento del joven Heidegger, al menos hasta la aparición de Ser y tiempo, y, de paso, romper así con el hechizo de una obra sin historia previa. Precisamente, la posibilidad de disponer de toda esta nueva base textual ha despertado el interés de los 
estudiosos por el pensamiento del joven Heidegger, tal como muestra la cascada de investigaciones aparecidas en estos últimos años ${ }^{13}$.

Para nosotros, estas lecciones de juventud de Friburgo (1919-1923) y, por extensión, las de Marburgo (1924-1928) no constituyen una etapa independiente, como sostienen, por ejemplo, Figal, Gander y Gadamer, ni forman diversas etapas evolutivas como defienden Pöggeler y Kisiel, sino que deben leerse desde el horizonte de Ser y tiempo, como un camino que desemboca en Ser y tiempo. El mismo Heidegger lo dejó claro en su texto retrospectivo $\mathrm{Mi}$ camino en la fenomenología: "El camino del pensar acabaría siendo más largo de lo que yo sospechaba y requirió de muchas paradas, de muchos rodeos y desvíos. Los primeros cursos de Friburgo y luego de Marburgo muestran el camino de un modo sólo indirecto"'|4. A este respecto, nos parece acertada la apreciación de Xolocotzi de que tanto "la 'interpretación evolucionista' de Gadamer y Figal como la 'interpretación pluralista' de Pöggeler y Kisiel analizan las primeras lecciones independientemente de Ser y tiempo: ambas líneas de interpretación ven en las lecciones una obra acabada y no un estar en camino"15. Una vez más insistimos en la necesidad de interpretar las lecciones de juventud desde la óptica del programa filosófico que se va dibujando en el transcurso de los primeros años veinte y que queda claramente perfilado en Ser y tiempo: la pregunta por el sentido del ser.

${ }_{13}$ Cf. por ejemplo, Buren, J., The Young Heidegger. Rumor of the Hidden King, Bloomington/ Indianápolis: Indiana University Press, 1994; Courtine, J.F. (ed.), Heidegger 1919-1929. De l'herméneutique de la facticité à la métaphysique du Dasein, París: J. Vrin, 1996; Denker, A. y H. Zaborowski (eds.), Heidegger Jahrbuch. I. Heidegger und die Anfänge seines Denkens, Friburgo: Karl Alber Verlag, 2004; Kisiel, Th., The Genesis of Heidegger's Being and Time, Berkeley/Los Ángeles: University of California Press, 1993; Buren, J. y Th. Kisiel (eds.), Reading Heidegger from the Start. Essays in His Earliest Thought, Albany: State University of New York, 1994; Quesne, P., Les recherches philosophiques du jeune Heidegger, Dordrecht: Kluwer Academic Press, 2003; Zahavi, D., S. Overgaard y Th. Schwarz (eds.), Den unge Heidegger, Copenhague: Akademisk Forlag, 2003. Y en el ámbito castellano contamos, entre otros, con: Adrián, J., Heidegger y la genealogía de la pregunta por el ser. Una articulación temática y metodológica de su obra temprana, Barcelona: Herder, 20I0; Berciano, M., La revolución filosófica de Martin Heidegger, Madrid: Biblioteca Nueva, 200I; Rodríguez, R., La transformación hermenéutica de la fenomenología. Una interpretación de la obra temprana de Heidegger, Madrid: Tecnos, 1997; Xolocotzi, A., Fenomenología de la vida fáctica. Heidegger y su camino a Ser y tiempo, México D.F.: Plaza y Valdés, 2004.

${ }^{14}$ Heidegger, M., “Mein Weg in die Phänomenologie”, p. 87.

15 Xolocotzi, A., Fenomenología de la vida fáctica. Heidegger y su camino a Ser y tiempo, p. 36. 
Esquemáticamente, las lecciones que inauguran la actividad académica de Heidegger en pleno período de posguerra se plantean el reto de elaborar un nuevo concepto de filosofía, que no encorsete y someta el fenómeno de la vida a los patrones científicos de conocimiento. El tono "existencialista" salta a la vista y caracteriza buena parte de la obra temprana de Heidegger. Una y otra vez surge la misma pregunta: icómo es posible aprehender genuinamente el fenómeno de la vida sin hacer uso del instrumental tendencialmente objetivante de la tradición filosófica? La respuesta es tajante: hay que suspender la primacía de la actitud teórica y poner entre paréntesis el ideal dominante de las ciencias físicas y matemáticas que impregna el quehacer filosófico desde Descartes hasta Husserl. El resultado final de esta tarea de lento y sistemático escrutinio de las verdaderas estructuras ontológicas de la vida humana queda reflejado en los diferentes y recurrentes análisis del tejido ontológico de la existencia humana que Heidegger lleva a cabo en el transcurso de la década de los años veinte: en 1919 se habla de una ciencia originaria de la vida; en 1922, de una ontología fenomenológica de la vida fáctica; en 1923, de una hermenéutica de la facticidad; en 1925 y en 1927, de una analítica existenciaria del Dasein; en 1928, de una metafísica del Dasein. He ahí el núcleo en torno al cual gira el quehacer filosófico del joven Heidegger hasta la publicación de Ser y tiempo: mostrar fenomenológicamente las diferentes formas de ser del Dasein para, desde ahí, aprehender el sentido del ser desde el horizonte de la historicidad y de la temporalidad.

Heidegger se deja llevar-más de lo que él mismo reconoce-por esta tendencia a descubrir la realidad de la vida, el motor que pone en movimiento todo el edificio de la filosofía. Schopenhauer mostró la voluntad como el verdadero fondo de la razón, Kierkegaard dejó claro que el pensamiento abstracto sacrifica la existencia concreta en aras de una verdad absoluta, Marx descubrió que la economía mueve al espíritu, Nietzsche y Freud destacaron los instintos que laten bajo la cultura... iY Heidegger? Él penetra en las potencialidades de la vida, que son el verdadero lugar de producción de las imágenes del mundo. Heidegger insiste sin cesar en que no se debe filosofar sobre la vida, sino desde ella. Una vida que cae en el vacío y que ya no se sostiene en ninguna instancia metafísica; una vida que hay que asumir con sus riesgos y con sus enigmas, pues quien quiera comprenderse a sí mismo ha de aclararse sobre la situación en la que se encuentra. Más que establecer un sistema de la vida, más que señalar la existencia de una nueva realidad, se trata de pensar la vida 
y su historia como el mar en el que ya se está navegando. Todos los hombres viven en la historia, pero muchos no lo saben. Otros saben que su tiempo es histórico, pero no lo viven como tal.

En definitiva, puede afirmarse que la pregunta en torno a la cual pivota el pensamiento de este primer Heidegger es la pregunta por el sentido mismo de la vida fáctica, tal como lo atestigua el currículo que redactó en 1922 para optar por una plaza de profesor titular en la Universidad de Gotinga: "Las investigaciones que sustentan la totalidad del trabajo realizado de cara a mis lecciones van encaminadas a una sistemática interpretación ontológicofenomenológica del problema fundamental de la vida fáctica"16. La vida humana y su comprensión del ser son los ejes que vertebran buena parte de la obra temprana de Heidegger. El caleidoscopio de referencias filosóficas que encontramos en esta fructífera etapa ofrece una imagen bastante fidedigna de la genealogía de esa pregunta y de los requisitos metodológicos necesarios para desarrollarla con éxito.

De esta manera, el intento heideggeriano de aprehender la realidad primaria de la vida humana pasa por dos decisiones fundamentales ${ }^{17}$. En primer lugar, una decisión eminentemente metodológica, que ya en los cursos universitarios de 1919 le lleva a un desmontaje crítico de la historia de la metafísica y a una transformación hermenéutica de la fenomenología de Husserl. Dos momentos imprescindibles de su método filosófico: un momento destructivo y otro momento constructivo. El primero destapa el intrincado mapa conceptual de la filosofía y retrotrae el fenómeno de la vida a su estado originario. El segundo propone un análisis formal de los diversos modos de realizarse la vida en su proceso de gestación histórica. Sin ellos resulta vano aventurarse en la senda de una articulación categorial del ámbito de donación inmediato de la vida fáctica y de su carácter ontológico.

${ }^{16}$ Heidegger, M., "Vita”, en: Reden und andere Zeugnisse eines Lebensweges (GA I6), Frankfurt del Meno: Vittorio Klostermann, 2000, p. 44. Esas investigaciones, iniciadas alrededor de 1919/20 en el marco de la discusión con la hermenéutica, el vitalismo, el neokantismo y la escolástica, cristalizan luego en el Informe Natorp (1922) y en las lecciones Ontología. Hermenéutica de la facticidad (1923).

17 Para más información, nos permitimos remitir a algunos de nuestros trabajos previos: Adrián, J., "Der junge Heidegger und der Horizont der Seinsfrage”, en: Heidegger Studien, XVII (200I), pp. II-2I y Adrián, J., El programa filosófico del joven Heidegger, Barcelona: Herder, 2009, pp. $\mid \mathrm{II}-2 \mathrm{I}$. 
En segundo lugar, una decisión temática que, en los primeros años de Friburgo, también desemboca en un análisis sistemático de las estructuras ontológicas de la vida humana. Precisamente, la pregunta por el sentido del ser de la vida ateorética y arreflexiva proporciona el punto de partida y facilita el hilo conductor de la pregunta por el ser en general. A partir de este planteamiento y una vez completada metodológicamente la hermenéutica fenomenológica del Dasein, vemos cómo la pregunta por el ser va adquiriendo cada vez más protagonismo en las lecciones de Marburgo (1924-1927) hasta convertirse en el tema central de Ser y tiempo. La gradual publicación de las primeras lecciones de Friburgo y de las lecciones de Marburgo ha venido a confirmar la idea de que el programa filosófico del joven Heidegger empieza a tomar forma en estos años.

Estos dos elementos, estos dos momentos se desarrollan simultáneamente a partir de las primeras lecciones de Friburgo. No es que primero se analicen las estructuras ontológicas de la vida fáctica y después se desarrolle la fenomenología hermenéutica, ya que el mismo descubrimiento y el análisis de esas estructuras precisa de antemano del método hermenéutico-fenomenológico. $Y$ tampoco es que primero se produzca la transformación hermenéutica de la fenomenología, porque esa transformación se lleva a cabo precisamente como resultado de la necesidad de hallar un método alternativo al de la fenomenología husserliana capaz de aprehender el significado de la vida. El tema y el método son dos elementos inseparables. De hecho, el método queda definido por el tema mismo: la vida fáctica.

Estos dos ejes quedan claramente definidos en el que podemos considerar el primer escrito programático del joven Heidegger, el Informe Natorp de 1922. La publicación de las primeras lecciones de Friburgo ha venido a confirmar la sospecha de que su programa filosófico se fragua en estos primeros años, al mismo tiempo que aporta un material documental de enorme valor para reconstruir la génesis de Ser y tiempo. La evidencia textual de la que disponemos en la actualidad permite ver cómo Heidegger empieza a organizar y sistematizar las líneas maestras de su pensamiento ya desde el curso de posguerra de 1919, intitulado La idea de la filosofía y el problema de la concepción del mundo. Esto significa posicionarse críticamente frente a su pasado escolástico y su formación neokantiana, integrar los elementos de la influyente lectura de Dilthey y, en particular, exprimir su redescubrimiento de Aristóteles y matizar 
su distanciamiento crítico de la fenomenología de Husserl. Las fuerzas de Heidegger se concentran durante estos años en ofrecer una interpretación dinámica de la vida. Las categorías filosóficas que sirven para escrutarla en su movilidad dan indicaciones de cómo se despliega temporalmente la existencia humana en sus posibilidades siempre limitadas. No se pretende categorizar ni, por tanto, detener el flujo de la vida, sino únicamente abrir un horizonte de apropiación. Solo así, recuperando las raíces originarias de la vida humana, se abre la posibilidad de una comprensión auténtica de su ser. La interpretación del ser del Dasein es un proceso y exige un esfuerzo constante que no se conforma con atrapar la vida en redes teóricas, fijarla en esquemas conceptuales rígidos y proyectarla en cosmovisiones tranquilizadoras.

El joven Heidegger dedicó varios años de investigación a esta tarea, en los cuales, como es sabido, no publicó nada ${ }^{18}$. Los doce años de silencio que se extienden entre 1915 y 1927 deben verse como una etapa de trabajo solitario en su laboratorio filosófico, es decir, como una lenta y sólida preparación de cara a un planteamiento expreso de la pregunta por el sentido del ser: en el período de juventud, esta pregunta se elabora a partir del modo de ser de la vida fáctica; en el Heidegger posterior, se adopta la perspectiva del acontecimiento apropiador (Ereignis). En otras palabras, la pregunta por el ser se despliega desde dos perspectivas: por una parte, desde la de la ontología fundamental $y$, por otra, desde la del pensamiento del acontecimiento histórico del ser. La primera se concreta en Ser y tiempo (1927), mientras que la segunda se plasma en Contribuciones a la filosofía (1936-1938).

En una breve retrospectiva de su propio camino filosófico, redactada entre 1937 y 1938 con el título Mein bisheriger Weg (Mi camino hasta ahora) y en la que remonta a su tesis doctoral, sus primeros cursos de Friburgo, así como a sus tempranas lecturas de Aristóteles y Husserl, el propio Heidegger reconoce que Ser y tiempo es el primer intento de pensar a fondo la pregunta por el sentido del ser desde la perspectiva de una ontología de la vida humana:

\footnotetext{
18 Véase la explicación ofrecida en “De un diálogo sobre el lenguaje” (en: Heidegger, M., Unterwegs zur Sprache, Pfullingen: Neske, 1990, p. 92) y la carta dirigida en 1922 a Karl Jaspers en la que se destaca la importancia de ocuparse prioritariamente de la comprensión del sentido del ser de la vida más que de atender a las exigencias académicas de una publicación (cf. Heidegger, M. y K. Jaspers, Briefwechsel 1920-1963, Múnich/Frankfurt del Meno: Piper/Vittorio Klostermann,
} 74 pp. 27-28). 
"Esta ontología no se concibió como un tratado 'regional' de la pregunta por el hombre, sino como fundamentación de la pregunta por el ente en cuanto tal -como una confrontación al mismo tiempo con el inicio de la metafísica occidental que arranca con los griegos"' 19 . Los esfuerzos de los siguientes diez años posteriores a la publicación de Ser y tiempo tan solo muestran la dificultad de pensar la verdad del ser y su relación con el Dasein de una manera totalmente nueva y más originaria desde la óptica ontohistórica, es decir, en el marco de la historia del $\operatorname{ser}^{20}$. La obra de Heidegger, como reza la plástica fórmula Wege, nicht Werke! (Caminos, no obras) que encabeza la edición de la Gesamtausgabe, debe entenderse propiamente como trayecto. No en el sentido de un recorrido que obedeciera a una decisión metodológica y cuyas fases se pudieran reconstruir a posteriori, sino como reconocimiento del esencial carácter itinerante de la filosofía misma en su insondable capacidad interrogativa. La filosofía, en especial la de los grandes pensadores como Platón, Aristóteles, Descartes, Kant, Hegel, Nietzsche y Heidegger, consiste básicamente en la modificación de la mirada a partir de una serie de preguntas fundamentales que nos descubren el mundo desde una perspectiva nueva.

${ }_{19}$ Heidegger, M., “Mein bisheriger Weg (Anhang: Ein Rückblick auf den Weg) ”, en: Besinnung (GA 66), Frankfurt del Meno: Vittorio Klostermann, 1997, p. 413 (cursiva y entrecomillado del autor).

${ }^{20}$ Cf. ibid., pp. 4I4-4I5. 